\title{
Pneumomediastinum: a complication of exposure to bromine
}

\author{
Izidore S Lossos, Igor Abolnik, Raphael Breuer
}

Although bromine is a potent respiratory irritant, there are few reports of pulmonary complications secondary to exposure to bromine. ${ }^{1}$ We report on a patient who developed cough with severe bronchospasm and spontaneous pneumomediastinum following accidental exposure to bromine. This appears to be the first published account of spontaneous pneumomediastinum after bromine inhalation.

\section{Case report}

A 21 year old man was admitted to the emergency ward after exposure to bromine. The patient worked as a maintenance technician in a chemical company. Two hours before admission, while exchanging pipes, one of the check valves ruptured leading to a rapid leakage of bromine. The patient experienced an immediate burning sensation on his face and started coughing. On admission, the patient was coughing and choking. Physical examination showed tachypnea of 24 breaths a minute, diffuse expiratory wheezes, and prolonged expirium. Grade I-II chemical burns were present on the anterior chest and face, sparing the eyes, which were protected by glasses. The rest of the physical examination was unremarkable. Arterial gases while breathing room air showed $\mathrm{Po}_{2} 67 \mathrm{~mm} \mathrm{Hg}, \mathrm{PCO}_{2} 52 \mathrm{~mm} \mathrm{Hg}$, and $\mathrm{pH}$ $7 \cdot 31$. Chest films showed no abnormality. Oxygen and an intravenous infusion of aminophyline and hydrocortisone were given and the patient was admitted to the medical intensive care unit. A few hours later the patient still experienced severe cough, and a chest $x$ ray film showed pneumomediastinum. No evidence of subcutaneous emphysema or chemical pneumonitis was present. Progressive improvement and resolution of mediastinal air occurred and the patient was discharged from hospital four days later. Surveillance chest $x$ ray film and pulmonary function tests were normal.

\section{Discussion}

Spontaneous pneumomediastinum was first reported in 1939 by Hamman. ${ }^{2}$ Macklin and Macklin ${ }^{3}$ suggested that it results from the rupture of marginal pulmonary alveoli, allowing bubbles of air to dissect to the mediastinum along the vascular sheaths and

Pulmonary Unit, Hadassah University Hospital, Jerusalem, Israel

I S Lossos, I Abolnik, R Breuer connective tissue planes. The rupture of marginal pulmonary alveoli frequently occurs after acute transient respiratory obstruction that may be caused by vomiting, sneezing, coughing, weight lifting, childbirth, and asthmatic attack. ${ }^{4}$

Bromine is widely used in industry, being implicated in the production of fumigants, fire retardants, flameproofing materials, and intermediate compounds in the production of dyes and films. ${ }^{5}$ Accidental exposure to bromine may result in burns, ${ }^{6}$ irritation of the oral mucosae and eyes, and the development of bronchospasm or chemical pneumonitis. ${ }^{1}$

Irritation of airways by bromine in our patient resulted in coughing and transient respiratory obstruction leading to rupture of marginal alveoli and mediastinal emphysema.

It is worthy of note that in the present case the chest roentgenogram taken on admission was normal and only surveillance chest $x$ ray film taken a few hours later showed the presence of pneumomediastinum. Its presence was previously masked by symptoms and signs that were solely attributed to exposure to bromine. Spontaneous pneumomediastinum is usually a benign, self limited condition, unassociated with a long term sequel. Prompt identification may prevent unnecessary diagnostic and therapeutic intervention and allow reassurance of the patient as to good outcome. Vigilance and examination of routine chest $x$ ray film may be the only way to diagnose this entity.

Requests for reprints to: Dr R Breuer, Pulmonary Unit, Hadassah University Hospital, POB 12000, IL 91120 , Jerusalem, Israel.

1 Kraut A, Lilis R. Chemical pneumonitis due to exposure to bromine compounds. Chest 1988;94:208-210.

2 Hamman L. Spontaneous mediastinal emphysema. Bulletin of the Johns Hopkins Hospital 1939;64:1-21.

3 Macklin MT, Macklin CC. Malignant interstitial emphysema of the lungs and mediastinum as an important occult complication in many respiratory diseases and other conditions: interpretation of clinical literature in light of laboratory experiment. Medicine 1944;23:281-358.

4 Munsell WP. Pneumomediastinum. JAMA 1967;202:129-33.

5 Stokinger HG. The halogens and non metals boron and silicon. In: Clayton GD, Clayton FE, eds. Patty's industrial hygiene and toxicology, 3rd revised ed. New York: John Wiley and Sons Inc, 1981:2965-71.

6 Sagi A, Baruchin AM, Ben-Yakar V, Kon M, Eyal A, Mahler D. Burns caused by bromine and some of its compounds. Burns 1985;11:343-50.

Accepted 11 June 1990 